\title{
Preferência alimentar de juvenis de lambari-cachorro, Oligosarcus hepsetus, em relação a duas espécies de presas de peixe em ambiente controlado
}

\author{
Feeding preference by juvenile pike characin, Oligosarcus hepsetus, on two \\ prey fish species of fish in a controlled environment
}

\author{
Alejandra Filippo Gonzalez Neves dos Santos ${ }^{\mathrm{I}}$ Pedro Ribeiro de Oliveira Carrera \\ Marcos Aronovich ${ }^{\mathrm{III}}$ Luciano Neves dos Santos ${ }^{\mathrm{IV}}$
}

\section{RESUMO}

O presente trabalho foi baseado em dados pretéritos sobre a dieta natural do lambari-cachorro Oligosarcus hepsetus em um reservatório do Sudeste brasileiro, e com isso foi testada a preferência alimentar desse carnívoro, a partir de experimentos com microcosmos. Os experimentos foram realizados em aquários, em janeiro de 2011. Os predadores foram coletados em um tributário do Rio Paraíba do Sul, enquanto as presas: Tilápia rendalli e o lambari, Astyanax fasciatus, foram adquiridas em pisciculturas. Foi testada a preferência alimentar do lambari-cachorro quanto ao tamanho das presas e às espécies-presa e os resultados foram relacionados com a energia da presa. O lambari-cachorro predou tilápia de menores comprimentos (CT) e alturas do corpo (AC), ao passo que não foi observado um padrão evidente de consumo de lambaris. Nos experimentos com CT padronizado, lambari-cachorro consumiu preferencialmente tilápias a lambaris, enquanto, nos experimentos com AC padronizada, não foram detectadas preferências no consumo por determinada espécie-presa. Diferenças energéticas entre espécies-presa parecem importar menos que diferenças morfológicas na preferência alimentar do lambari-cachorro.

Palavras-chave: Characiformes, Rio Paraiba do Sul, peixe nativo.

\section{ABSTRACT}

This study was based on previously published data on natural diet of the pike characin, Oligosarcus hepsetus in a reservoir at Southeastern Brazil, and thus tested the feeding preference of this carnivore using microcosm experiments. The experiments were conducted in aquariums, in January 2011. Predators were collected in a tributary of the Paraiba do Sul River, while preys: Tilapia rendalli and Astyanax fasciatus were obtained of fish farms. We tested the feeding preference by pike characin in relation to prey size and species, and the results were compared to prey energy. Juvenile pike characin predated preferentially on tilapias with lower body length height, whereas no clear pattern of consumption was observed for lambaris. Tilapias were preferentially predated at experiments with standardized prey body length, whereas no feeding preference was recorded on any prey species at experiments with standardized prey body height. Energetic differences between prey species seem to be less important than morphological differences for the feeding preference of pike characin.

Key words: Characiforms, Paraiba do Sul River basin, native fish.

\section{INTRODUÇÃO}

No último século, com a expansão das atividades comerciais e a melhoria no transporte mundial, a introdução de espécies não-nativas se intensificou dramaticamente, a ponto da banalização, sendo a Aquicultura considerada o principal vetor de organismos aquáticos invasores (ASHLEY, 2007). Atualmente, a introdução de espécies atinge todas as regiões do planeta, e este fenômeno, em razão da série de efeitos negativos que o acompanha, tem sido considerado como uma das maiores ameaças à biodiversidade e ao funcionamento dos ecossistemas naturais (SANTOS et al., 2004). Nesse sentido, torna-se indispensável a implantação de medidas de controle de espécies não-nativas, uma vez que se desconhecem os custos ecológicos e econômicos que estas podem acarretar.

Existem amplas informações sobre o efeito de espécies predadoras em peixes forrageiros,

\footnotetext{
'Departamento de Zootecnia e Desenvolvimento Agrossocioambiental Sustentável, Universidade Federal Fluminense (UFF), Rua Vital Brasil Filho 64, 24230-340, Niterói, RJ, Brasil. E-mail: alejandrafilippo@hotmail.com. Autor para correspondência.

IIFaculdade de Veterinária, UFF, Niterói, RJ, Brasil.

IIICentro de Pesquisa em Sanidade Animal Geraldo Manhães Carneiro (PESAGRO Rio), Niterói, RJ, Brasil.

${ }^{\text {IV } U n i v e r s i d a d e ~ F e d e r a l ~ d o ~ E s t a d o ~ d o ~ R i o ~ d e ~ J a n e i r o ~(U N I R I O), ~ R i o ~ d e ~ J a n e i r o, ~ R J, ~ B r a s i l . ~}$ Recebido 14.03.13 Aprovado 29.08.13 Devolvido pelo autor 05.12.13 CR-2013-0345.R1
} 
porém, com exceção de SANTOS et al. (2009), não há registros sobre o uso de peixes carnívoros nativos no controle da ictiofauna invasora em ecossistemas aquáticos continentais. Impactos significativos à ictiofauna nativa não são esperados pelo uso de peixes carnívoros nativos, uma vez que, em princípio, predadores e presas nativos vêm co-evoluindo ao longo do tempo e desenvolvendo mecanismos de predação e defesa ecologicamente sustentáveis.

O objetivo deste trabalho foi investigar a preferência alimentar do lambari-cachorro, Oligosarcus hepsetus, peixe carnívoro nativo da bacia do Rio Paraíba do Sul, sobre a tilápia, Tilapia rendalli (espécie exótica) e o lambari, Astyanax fasciatus (espécie nativa).

A tilápia é considerada uma espécie invasora em inúmeros ecossistemas aquáticos continentais, principalmente em virtude de escapes de sistemas de produção em cativeiro. No rio Paraíba do Sul, a tilápia foi introduzida desde a década de 50, visando ao controle de vegetações aquáticas, porém atualmente é caracterizada como catalisadora de impactos ambientais (SILVA et al., 2002). A escolha da tilápia para o presente estudo foi devido a seus estabelecimentos (se autossustenta quanto à reprodução e recrutamento) em muitos ecossistemas desta bacia, bem como seus prováveis impactos sobre as espécies nativas. Por outro lado, o lambari foi selecionado devido a sua elevada abundância, ampla distribuição no rio Paraíba do Sul e por ser presa por excelência neste ecossistema, de forma a aumentar o conhecimento das interações predador-presa entre espécies nativas e introduzidas.

Nesse contexto, a importância deste estudo é o conhecimento sobre a preferência alimentar deste predador em relação a duas espécies de peixes em ambiente controlado, a fim de adquirir dados para futuros programas de cultivo desta espécie em cativeiro, visando ao repovoamento e recuperação de seus estoques naturais, que, além de estimularem o cultivo de espécies nativas brasileiras, poderão contribuir na formulação de medidas de manejo para o controle de espécies invasoras em ecossistemas aquáticos continentais.

\section{MATERIAL E MÉTODOS}

Seleção e aquisição das espécies para o experimento

O presente estudo foi baseado em dados pretéritos da dieta natural do lambari-cachorro, espécie de peixe carnívoro nativo da bacia do rio Paraíba do Sul, realizado por SANTOS et al. (2004). O lambaricachorro vem sendo o principal item alimentar das espécies do gênero Cichla, espécies invasoras nesta bacia (SANTOS et al., 2004), indicando que, num futuro próximo, sua população tende a deplecionar em consequência desta predação. Por outro lado, o lambari-cachorro, no ambiente natural, preda intensamente espécies invasoras, como tucunarés e tilápias, sendo um potencial predador natural para controle dessas espécies. Com base nisso, foi testada a preferência alimentar desse predador, através de experimentos em aquários, usando espécies-presa nativa e exótica.

Para a execução experimental, o predador foi obtido, por meio de coletas em redes de espera com malhas de tamanhos variados, com anzol e linha em um afluente do rio Paraíba do Sul - Barra do Piraí, RJ, Brasil, enquanto as presas foram adquiridas em estações de piscicultura de Belo Horizonte, MG, Brasil. Foram selecionadas como presas uma espécie nativa, o lambari, e uma invasora, a tilápia, para testar a preferência dessas espécies-presa por este predador.

\section{Ensaios experimentais}

Inicialmente, o predador e as presas foram aclimatados por um período de cinco dias em tanques de polietileno de $50 \mathrm{~L}$ e aquários de 65L. Esses tanques e aquários foram abastecidos por água sem cloro. Todos os tanques e aquários foram providos de aeradores e cobertos com telas sombrite $50 \%$ para evitar possíveis fugas. Como medida preventiva de possíveis infecções, estes peixes recém-chegados foram submetidos a banhos de curta duração com cloreto de sódio como medida profilática rotineira. Os predadores, durante esse período, ficaram de jejum enquanto as presas foram alimentadas com ração farelada comercial (30\% de proteína e $3145 \mathrm{kcal} / \mathrm{kg}$ de energia digestível) três vezes ao dia.

Os experimentos foram realizados em quatro aquários de $65 \mathrm{~L}(31 \times 63 \times 42 \mathrm{~cm})$, no Laboratório de Aquicultura da UFF - Faculdade de Veterinária, Niterói - RJ, providos de aeradores, sendo a temperatura da água monitorada quatro vezes ao dia através de termômetros.

No início e término dos experimentos, os predadores e as presas foram anestesiados com eugenol (5 $\mathrm{ml}_{2} \mathrm{LL}^{-1}$ de água) (SANTOS et al., 2009), identificados, contados e medidos em seu comprimento total (CT), sendo também medidas a altura do corpo (AC) das presas e a altura e largura da boca dos predadores. As estruturas morfométricas dos predadores e das obtidas das presas foram medidas com auxílio de ictiômetro, baseadas em KEAST \& WEBB (1966): a) comprimento total - distância da ponta do focinho até a ponta da nadadeira caudal; 
b) altura da boca - distância vertical, medida na porção interna da boca, entre os ângulos da maxila e mandíbula; c) altura do corpo - distância vertical, medida entre os ângulos formados pelo dorso e o ventre; d) largura do corpo - distancia horizontal, medida entre os ângulos formados pelo ventre.

Experimento 1 - Preferência do predador em relação ao tamanho da presa

Foram estocados, em um aquário, um lambari-cachorro (CT-15-20cm) junto com oito indivíduos de cada espécie-presa em separado. Foram separadas quatro classes de comprimento total (CT) $(25 \leq 30 ; 31 \leq 35 ; 36 \leq 40 ; 41 \leq 45 \mathrm{~mm})$, variando entre $12,5 \%$ e $50 \%$ do CT do predador, sendo utilizados dois indivíduos-presa de cada CT de cada espécie-presa.

Foram realizadas quatro réplicas desse experimento e, após o consumo de 3-4 presas em cada aquário, o experimento foi interrompido. Após a realização dos experimentos para tilapia como espécie-presa, os experimentos foram repetidos para o lambari. Tais experimentos visaram a identificar se os predadores nativos apresentam consumo preferencial sobre uma determinada classe de tamanho (CT) das espécies-presa oferecidas.

Após a conclusão do experimento, mantendo-se o CT das presas, foi realizado outro, similar, mantendo-se a altura do corpo das presas ( $\leq 50 \%$ da altura da boca do predador), no qual foram separadas quatro classes de altura do corpo (AC) das presas: $7,0 \leq 7,5 ; 7,6 \leq 8,0 ; 8,1 \leq 8,5 ; 8,6 \leq 9,0 \mathrm{~mm}$.

Experimento 2 - Preferência do predador em relação à espécie-presa

Para testar a preferência com relação à espécie-presa, um indivíduo de lambari-cachorro com comprimento total (CT) entre $15-20 \mathrm{~cm}$ foi mantido em um aquário junto com oito indivíduos-presa: quatro de tilapia e quatro de lambari. Em virtude dos resultados de maior consumo das espécies-presa em determinada classe de tamanho, observado no experimento anterior, neste experimento, as presas de ambas as espécies foram mantidas intencionalmente com comprimentos similares de $26 \leq 30 \mathrm{~mm}$, diferindo apenas na altura e largura de seus corpos, em função de caracteres morfológicos próprios de cada espécie. Após a conclusão do experimento, mantendo-se o CT das presas constante, foi realizado outro similar, mantendo uma altura do corpo (AC) das presas de 7,6 $\leq 8,0 \mathrm{~mm}$ (classe mais consumida de ambas espécies no experimento 1 ).

Foram realizadas quatro réplicas para cada um destes experimentos (CT e AC) e, após o registro do consumo de 3-4 presas em cada aquário, o experimento foi interrompido. Tais experimentos visaram a identificar os padrões de preferência do predador sobre as espécies-presa oferecidas, inferindo os padrões causais de seu comportamento predatório.

Experimento 3 - Calorimetria

Para este experimento, foram analisados os valores energéticos de 10 indivíduos de cada classe de CT $(25 \leq 30 ; 30 \leq 35 ; 35 \leq 40 ; 40 \leq 45 \mathrm{~mm})$ e 10 indivíduos de cada $\mathrm{AC}(7,0 \leq 7,5 ; 7,5 \leq 8,0$; $8,0 \leq 8,5 ; 8,5 \leq 9,0 \mathrm{~mm})$ de ambas espécies de tilapia e de lambari, através de calorimetria - metodologia amplamente empregada em estudos de bioenergética (CRAIG, 1978; BRYAN, 1996). Essa análise foi realizada no Centro de Pesquisa em Sanidade Animal Geraldo Manhães Carneiro - PESAGRO Rio.

As presas foram colocadas em recipientes com gelo, mortas, congeladas e levadas a uma estufa. Posteriormente, a matéria seca obtida foi direcionada para bombas calorimétricas que mediram o valor energético do tecido das presas através do calor liberado durante o processo de combustão (ENCINA \& GRANADO-LOURENCIO, 1997). A calorimetria foi calculada através dos dados de $\mathrm{Kcal} / \mathrm{g}$ x peso seco das amostras de diferentes classes de tamanho de CT e de $\mathrm{AC}$, sendo a energia bruta (EB) calculada através da fórmula:

$$
\begin{aligned}
& \Delta T=T f-T i \\
& E B(\text { Kcal } / g)=\frac{(\Delta T \times 2.541,32)-20}{\text { Pamostra }}
\end{aligned}
$$

Tratamento estatístico

No experimento 1, foi empregada a ANOVA unifatorial para comparação do consumo médio da tilápia com diferentes CT pelo lambaricachorro, seguido do teste post-hoc de Tukey em nível de $95 \%$ de confiança, para comparação de médias. Em seguida, o mesmo teste foi aplicado para o lambari. Também foi testado com mesma análise o consumo médio da tilápia com diferentes AC pelo lambari-cachorro e, posteriormente, o mesmo teste foi aplicado quanto ao consumo do lambari.

No experimento 2, foi aplicado o teste t de Student, no qual se compara a preferência do lambari-cachorro pela tilápia e lambari de mesmo CT e, posteriormente, o mesmo teste foi aplicado para a preferência do lambari-cachorro pela tilápia e lambari de mesma AC.

No experimento 3, foi empregada a ANOVA bifatorial, comparando os dados calorimétricos tanto da tilápia quanto do lambari por diferentes classes 
de CT, seguido do teste post-hoc de Tukey em nível de $95 \%$ de confiança, para comparação de médias. Posteriormente, o mesmo teste foi aplicado para AC.

\section{RESULTADOS E DISCUSSÃO}

No experimento 1, de acordo com ANOVA unifatorial, o lambari-cachorro selecionou diferentes classes de $\mathrm{CT}$ de lambari e de tilápia $(\mathrm{F}=14,6 ; \mathrm{P}<0,001$ para ambos), sendo observado maior consumo das classes $25 \leq 30$ e $36 \leq 40 \mathrm{~mm}$ para primeira espéciepresa e das classes $25 \leq 30$ e $31 \leq 35 \mathrm{~mm}$ para a segunda (Figura 1). O predador também selecionou diferentes classes de $\mathrm{AC}$ de lambari $(\mathrm{F}=9,3 ; \mathrm{P}=0,002)$ e de tilápia $(\mathrm{F}=25,3 ; \mathrm{P}<0,001)$, sendo observado um maior consumo das duas classes de menor AC $(7,0 \leq 7,5$ e $7,6 \leq 8,0 \mathrm{~mm})$ e da última classe $(8,6 \leq 9,0 \mathrm{~mm})$ para a primeira espécie-presa e das duas classes menor AC $(7,0 \leq 7,5$ e $7,6 \leq 8,0)$ para a segunda (Figura 2 ). Neste primeiro experimento, os resultados indicam que lambari-cachorro predou seletivamente sobre os indivíduos de tilápia de menores $\mathrm{CT}$ e $\mathrm{AC}$, ao passo que não foi observado um padrão evidente de consumo de lambaris, indicando que as características morfométricas influenciaram menos para a predação

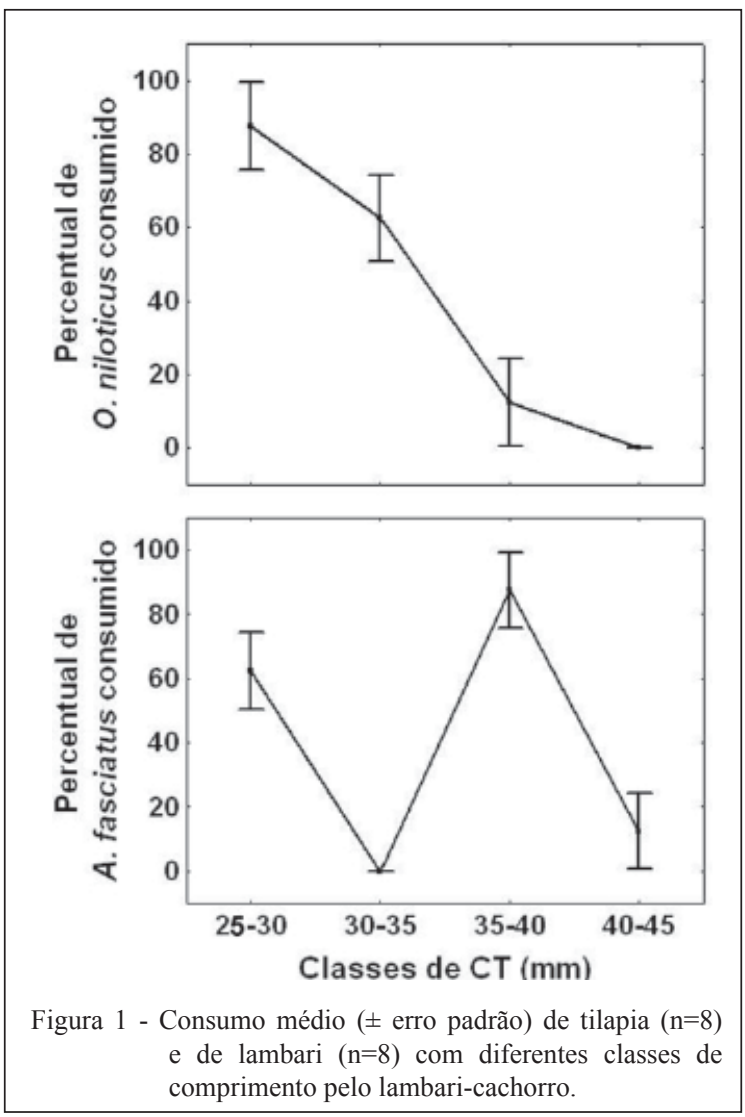

dessa espécie-presa nas faixas de CT e AC testadas (Figura 1 e 2).

No experimento 2, o predador consumiu preferencialmente tilápias a lambaris $(\mathrm{t}=5,2 ; \mathrm{P}=0,002)$, enquanto, nos experimentos com AC padronizada, não foram detectadas preferências no consumo por determinada espécie-presa $(\mathrm{t}=1,6 ; \mathrm{P}=0,168)$. Os resultados sugerem que a $\mathrm{AC}$ foi mais importante que CT na seleção de presas por lambari-cachorro, corroborando as teorias estabelecidas para peixes piscívoros que consomem presas inteiras (GILL, 2003; TRUEMPER \& LAUER, 2005). Nesse contexto, a altura do corpo representou um componente importante na seleção de presas por lambari-cachorro, que consumiu preferencialmente presas com AC próxima a $1 / 3(31,5 \%)$ da altura da sua boca. Sob o ponto de vista conservacionista, a espécie-presa nativa, ou seja, o lambari, é mais vulnerável à predação por lambari-cachorro do que a tilápia, uma vez que esta espécie-presa não-nativa, além de apresentar uma alta taxa de crescimento e de atingir tamanhos superiores ao do predador, apresenta uma janela de predação mais restrita aos indivíduos de pequeno porte (entre 26,4 e $31,5 \mathrm{~mm}$ de CT), que apresentaram as menores $\mathrm{AC}$ entre as presas oferecidas.

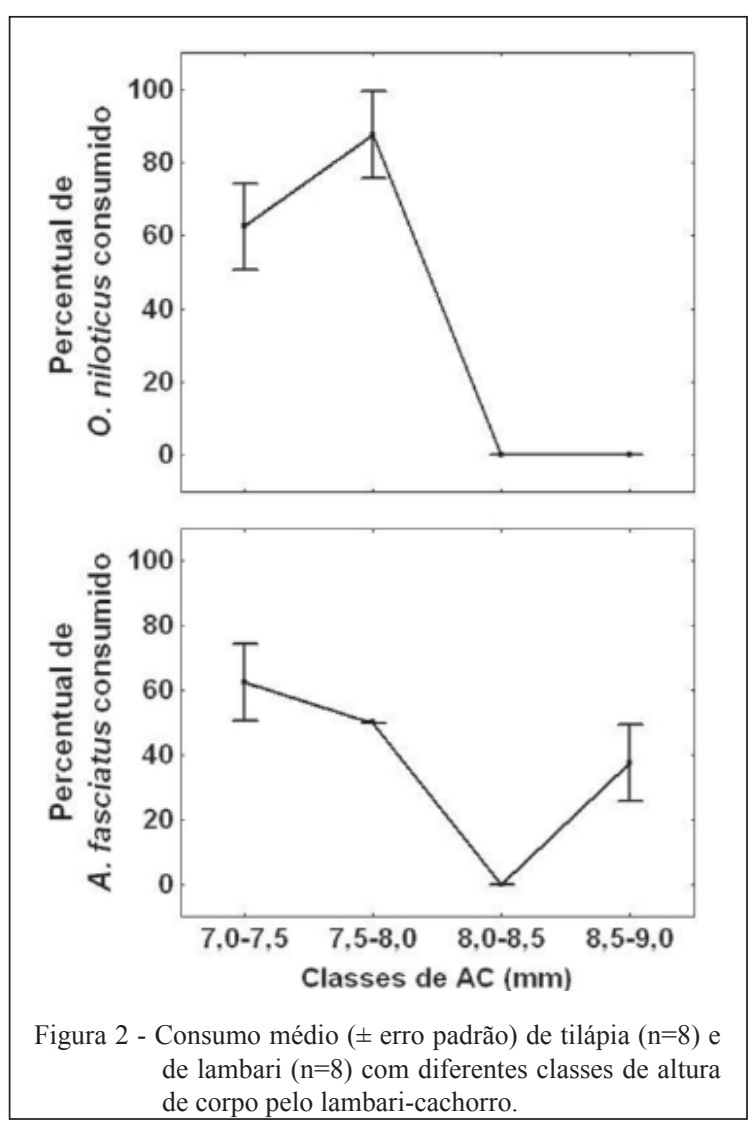

Ciência Rural, v.44, n.2, fev, 2014. 
No experimento 3, segundo a ANOVA bifatorial dos dados calorimétricos (Kcal g-1 $\mathrm{x}$ peso seco) por CT, houve interação significativa de classes $\mathrm{x}$ espécies $(\mathrm{F}=11,03 ; \mathrm{P}<0,01)$, não havendo diferenças significativas da calorimetria da classe $25-30 \mathrm{~mm}$ do lambari para a classe $30-35 \mathrm{~mm}$ da tilápia $(\mathrm{P}=0,99)$; entre a classe $30-35 \mathrm{~mm}$ do lambari e a classe 35 $40 \mathrm{~mm}$ da tilápia $(\mathrm{p}=0,58)$ e entre ambas as espécies na última classe $(40-45 \mathrm{~mm})(\mathrm{P}=0,54)$. Nesse contexto, houve diferença significativa de calorimetria por CT dentro de cada espécie, no entanto, entre espécies, foram observados menores valores calorimétricos para CT 25-30mm de tilápia $(\mathrm{P}<0,01)$, não havendo diferenças significativas para a calorimetria de CT da última classe para ambas espécies $(\mathrm{P}=0,54)$ (Figura 3).

Por outro lado, os dados de calorimetria de AC revelaram diferenças entre espécies $(\mathrm{F}=506,6$; $\mathrm{P}<0,01)$ e entre classes $(\mathrm{F}=39,5 ; \mathrm{P}<0,01)$, não exibindo interações significativas $(\mathrm{F}=1,1 ; \mathrm{P}=0,36)$. De maneira geral, dados calorimétricos de $\mathrm{AC}$ de lambari foram superiores aos da tilápia. A menor classe de AC do lambari apresentou menor valor calorimétrico significativo $(\mathrm{P}<0,01)$ e a maior classe, maior valor calorimétrico significativo $(\mathrm{P}<0,01)$, no entanto, as classes $7,0-7,5$ e $8,0-8,5$ de $\mathrm{AC}$ do lambari não apresentaram diferenças significativas entre si $(\mathrm{P}=0,07)$. A menor classe da $\mathrm{AC}$ da tilápia, por outro lado, apresentou menor valor calorimétrico significativo $(\mathrm{P}<0,01)$, no entanto, as últimas três classes: 7,5-8,0; 8,0-8,5 $(\mathrm{P}=0,99)$ e $8,5-9,0 \quad(\mathrm{P}=0,70)$ não apresentaram diferenças significativas (Figura 3 ).
Nossos resultados sugerem que diferenças energéticas entre espécies-presa parecem importar menos que diferenças morfológicas na preferência por lambari-cachorro. Juvenis desta espécie não percebem a diferença calorimétrica entre espécies-presa, porque, quando o CT das presas se mantém, eles se alimentam preferencialmente da tilápia, demonstrando maior percepção pelo volume da presa (por serem comparativamente mais altas), do que pelo próprio valor energético, que é justificado pelo menor consumo do lambari. O experimento de preferência utilizando AC, por exemplo, reforça isso.

Entretanto, como as características morfológicas do lambari influenciaram menos para a predação nas faixas de comprimento e altura do corpo testadas, devemos também considerar possíveis mecanismos de defesa comportamentais de coevolução entre predador e presa nativos, já que ambos (lambari-cachorro e lambari) co-evoluíram ao longo do tempo, desenvolvendo mecanismos de predação e defesa eficazes, mas ecologicamente sustentáveis, o que justifica, em parte, o reduzido consumo do lambari quando comparado à tilápia.

Nesse sentido, as características morfológicas e comportamentais, por serem fatores chave na piscivoria de peixes, podem ter contribuído para o padrão de consumo diferenciado entre espéciespresa observado no presente trabalho. De acordo com GILL (2003), quando a disponibilidade de diferentes espécies-presas é relativamente igual, presas de menor tamanho podem ser mais energeticamente proveitosas do que presas maiores, uma vez que os predadores tendem a alocar menos tempo ou energia
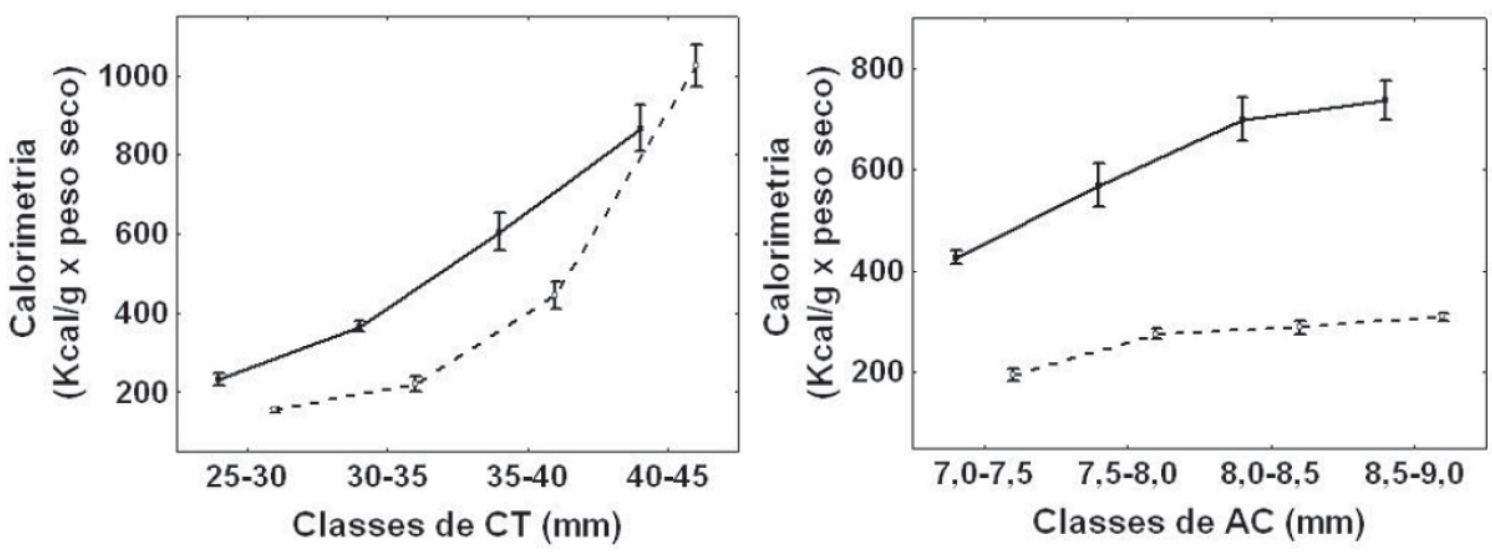

Figura 3 - Média dos dados calorimétricos (Kcal g-1 x peso seco) ( \pm erro padrão) da tilapia ( $\mathrm{n}=40)$ (tracejado) e do lambari ( $\mathrm{n}=40)$ (linha) por diferentes classes de CT e AC. 
na procura, captura e manipulação (handling time) de presas pequenas, diminuindo sua vulnerabilidade a predadores de maior porte ou cleptoparasitas. Segundo NILSSON \& BRONMARK (2000), diversos estudos têm demonstrado um forrageamento seletivo em predadores, que ingerem presas com tamanho inferior às dimensões de seus aparatos bucais, fato este que deve estar ligado à disponibilidade e facilidade de captura de presas, como predito pela teoria de forrageamento ótimo.

A teoria do forrageamento ótimo baseia-se em premissas para predizer a ingestão preferencial de presas pelo predador, a qual depende do tamanho e disponibilidade de presas e do tempo gasto na captura e manipulação das presas pelo predador (GILL, 2003; TURESSON et al., 2002). Segundo essa teoria, predadores que forrageiam mais eficientemente e otimizam sua obtenção de energia, maximizarão seu fitness ecológico e contribuirão com mais genes para as gerações futuras (KAHILAINEN \& LEHTONEN, 2003). Para que um predador otimize a taxa de energia, o ganho energético adquirido pela ingestão de presas deve ser avaliado contra o tempo necessário para essa aquisição e o tempo gasto na captura (JUANES, 1994; SANTOS \& BENEDITO-CECÍLIO, 2005).

Por fim, para podermos inferir medidas na elaboração e implementação de programas de manejo eficientes no controle biológico das espécies invasoras em ambientes naturais por predadores nativos, recomendamos a realização de estudos experimentais complementares a energia alimentar e morfológica, obtidas no presente estudo, para se quantificar os gastos energéticos do predador através do handling time, visando a complementar os principais fatores envolvidos na ingestão seletiva de presas nativas e introduzidas por lambari-cachorro.

\section{CONCLUSÃO}

A altura do corpo representou um componente importante na seleção de presas pelo lambari-cachorro. Sob o ponto de vista conservacionista, a espécie-presa nativa é mais vulnerável à predação do que a tilápia. No entanto, o potencial de controle de juvenis do lambari-cachorro sobre tilápias entre 25 e $35 \mathrm{~mm}$ de CT e entre 7 e $8 \mathrm{~mm}$ de AC, deve ser considerado. Nossos resultados também sugerem que diferenças energéticas entre espécies-presa parecem importar menos que diferenças morfométricas. As características morfométricas e comportamentais, por serem fatores chave na piscivoria de peixes, podem ter contribuído para o padrão de consumo diferenciado das presas.

\section{AGRADECIMENTOS}

À Pro-Reitoria de Pesquisa, Pós-Graduação e Inovação (PROPPI) - UFF, pela bolsa de iniciação científica e fomento à pesquisa.

\section{COMITÊ DE ÉTICA E BIOSSEGURANÇA}

Os experimentos do presente trabalho foram realizados com a aprovação do Comitê de Ética em Pesquisa Animal da UFF (CEPA).

\section{REFERÊNCIAS}

ASHLEY, P.J. Fish Welfare: Current issues in aquaculture. Applied Animal Behaviour Science, v.104, p.199-235, 2007.

BRYAN, S.D. Caloric densities of three predatory fishes and their prey in Lake Oahe, South Dakota. Journal of Freswatwer Ecology, v.11, p.153-161, 1996.

CRAIG, J.F. et al. Comparative estimation of the energy content of fish tissue from bomb calorimetry, wet oxidation and proximate analysis. Freshwater of Biology, v.8, p.585-590, 1978.

ENCINA, L.; GRANADO-LOURENCIO, C. Season variations in the physiological status and energy content of somatic and reproductive tissues of chub. Journal of Fish Biology, v.50, p.511-522, 1997.

GILL, A.B. The dynamics of prey choice in fish: the importance of prey size and satiation. Journal of Fish Biology, v.63, suppl a, p.105$116,2003$.

JUANES, F. What determines prey size selectivity in piscivorous fishes? Belle W Baruch Library in Marine Science, v.18, p.79100, 1994.

KAHILAINEN, K.; LEHTONEN, H. Piscivory and prey selection of four predator species in a whitefish dominated subarctic lake. Journal of Fish Biology, v.63, n.3, p.659-672, 2003.

KEAST, A.; WEBB, D. Mouth and body form relative to feeding ecology in the fish fauna of small lake Opinicon, Ontario. Journal of the Fisheries Research Board of Canada, v.23, p.1845-1874, 1966.

NILSSON, P.A.; BRÖNMARK C. Prey vulnerability to a gapesize limited predator: behavioural and morphological impacts on northern pike piscivory. Oikos, v.88, p.539-546, 2000.

SANTOS, A.F.G.N. et al. Could native predators help to control invasive fishes? Microcosm experiments with the characid Brycon orbignyanus. Ecology of Freshwater Fish, v.18, p.491-499, 2009.

SANTOS, A.F.G.N. et al. Alimentação de duas espécies de peixes carnívoros no Reservatório de Lajes, RJ. Revista Universidade Rural. Série Ciências da Vida, v.24, n.1, p.161-168, 2004.

SANTOS, E.C.; BENETITO-CECILIO, E. Ecologia energética de peixes: influencia de fatores bióticos e abióticos. Maringá: EDUEM, 2005.

SILVA, P.S. et al. Relação peso-comprimento da Tilapia rendalli no Reservatório de Lajes. In: JORNADA DE INICIAÇÃO CIENTÍFICA DA UFRRJ, 12., 2002, Seropédica, RJ. Anais Seropédica: UFRRJ, 2002. 
TRUEMPER, H.A.; LAUER, T.E. Gape limitation and piscine prey size-selection by yellow perch in the extreme southern area of Lake Michigan, with emphasis on two exotic prey items. Journal of Fish Biology, v.66, p.135-144, 2005.
TURESSON, H. et al. Prey size selection in piscivorous pikeperch (Stizostedion lucioperca) includes active prey choice. Ecology of Freshwater Fish, v.11, p.223-233, 2002 . 